\title{
Emotional Security on Teaching Effectiveness
}

\author{
Jonevee B. Amparo \\ University of the Philippines Visayas
}

\begin{abstract}
This paper identified factors and challenges in sustaining attention and academic connection in the classroom. Results show that there are things that teachers find important to get attention and to secure academic connection with the students like creating motivating activities, building an environment that nurture trust, love and confidence, and setting expectations and using varied instructional strategies and materials. The effect of emotional security on the teaching-learning process was also evaluated in this study in connection with factors that affect learning.

Classroom observations and interviews were made to gather data. The study will help educators and curriculum developers to consider various aspects of students' learning needs in the preparation and planning of instruction. It is a guide to know and resolve issues in the teaching-learning process as well as to consider some pedagogical practices that are not acknowledged in the classroom dynamics.
\end{abstract}

\section{Introduction}

Effective teaching and good teaching always intertwined with one another, and the difference between the two is always being discussed and brings about many perspectives in teaching. When you ask a child who their favorite teacher is, they will give you a name, and when you ask them why, they will often answer that the teacher is beautiful, kind, or nice. An adult's answer to this question will be far different and more elaborate. This differentiation will let us think and reminisce many of our teachers. It will take us into little details of what they did before, when we were under their supervision.

Effectiveness as a teacher means creating an impact on student's life by making him/her realize his skills, developing his potentials, and encouraging him/her to think critically. Effective teaching is guiding the student all the way in the process of learning and experiencing knowledge.

Bickel and Bickel [6] reviewed the effective teaching literature and summarized it as follows:

\footnotetext{
"What emerges across various commentaries is the image of effective teachers taking an active, direct role in the instructions of their students. These educators give many detailed and redundant instructions and explanations
}

when introducing a new concept. They give ample, opportunity for guided practice with frequent reviews of student progress. They check for understanding, using such techniques as questioning, consistent review of homework, and review of previous day's lessons before moving on to next areas. Such teachers move among students when they are involved in practice seatwork. Feedback is provided frequently and with meaningful detail. Effective teachers use feedback strategies for positive reinforcement of student success. Feedback also provides the basis for re-teaching where necessary. Effective teachers take an active role in creating a positive, expectant, and orderly classroom environment in which learning takes place. To accomplish these climate objectives, effective teachers actively structure the learning process and management of time, building in such things as signals for academic work and maintaining student attention by group alerting and accountability techniques through variation in educational tasks."

The term good has many meanings depending on the context where it is used. This means "good teaching" is subjective. It may mean doing things that are not against the norms of the society, describing the quality of doing the job, and grounding on morality. The word "good" may also refers to a person possessing desirable qualities, adapted to answer the end designed, promoting success, welfare, or happiness, serviceable, useful, fit, excellent, admirable, and commendable.

The moral dimension in teaching is always held in the pedestal as teachers are models of ethics in the society.

A good teacher is knowledgeable and loves his profession, and he upholds virtues and standards; but these do not necessarily mean that the teaching has been effective, or the teacher is effective. A good teacher has the potentials to make the student learn and appreciate learning as teaching is a complex process that requires abilities and a passion to teach. Many qualities are associated to a good teacher. But what about effective teacher? What are the qualities of an effective teacher? What is more important in teaching effectively, the qualities or the process of teaching? 
The need for knowledge is the continuous pursuit in this life, and teacher is the key element to facilitate learning. Educators, professors, instructors and teachers have the core of learning foundation, and that is the practice of teaching. They guide the students in the learning process. They have different ways in dealing with difficulties of students. A student may have passed under the supervision of more than a dozen of teachers in his life. And there would be always teachers that created a great impact on their students' lives. Sometimes comparisons happen between who is good and who is an effective teacher. Descriptions and characteristics of both may sometimes be alike but ends with a deeper realization of which one should always be expected from a teacher.

Students should have the desire to learn or be motivated to learn before establishing academic connection. Teachers should have creativity to sustain attention. He or she should maximize resources to utilize it for activities or delivering the discussion. Creativity, as an aptitude exhibited by a great majority of teachers, describes their originality and inventiveness. Because it is inborn, it surfaces spontaneously, and every finished task is a mark of one's imaginative self. The great inventions and discoveries of scientists, some of whom spent some years in teaching, were unmistakably products of their creativity and risk-taking tendencies. In the end, they were able to invent or discover new things that we have been using up to now.

By knowing teachers' and students' classroom practices, dynamics, we will be able to fully understand the important underlying factors in learning.

Sustaining attention and academic connection among students are part of the routine in the transfer of knowledge in the classroom to effectively teach the lesson. Lived experiences of the teachers will let us unlock the factors that affect effective teaching, and how students' emotional security with the teacher can hasten and affects the learning process.

\section{Methodology}

Generally, this study aims to explore teachers' lived experiences in sustaining attention and academic connection.

Specifically, this study aims to:

1. Identify the challenges in trying to sustain the attention or interest and academic connection of students;

2. Identify the indicators that students sustained the attention and academic connection as perceived by the teachers; and 3. Evaluate the importance of emotional security in the teaching and learning process.
This study explored the lived experiences of the teachers by interview using questionnaires. It aimed to gather written consciousness of the participants and patterns of events and experiences about the given topic through analysis. These vast narratives will help explore the consciousness of the phenomenon. The participants are teachers taking their graduate degrees. This is a qualitative data that aims to extract information about a phenomenon as experienced by the participants.

The processes in the study involves: question formulating, Data chunking and Data naming Coding, Developing conceptual categories or themes.

Data were analyzed through thematic coding and analysis. The researcher also had classroom observations and interviews to validate the data gathered and to gather additional data. The themes extracted from the data are validated by an interrater. The Theory of Affect was used as a lens in explaining underlying factors in the teaching and learning process.

The study will help educators and curriculum developers to consider various aspects of students' learning needs in the preparation and planning of instruction. It is a guide to know and resolve issues in the teaching-learning process as well as to consider some pedagogical practices that are not acknowledged in the classroom dynamics. The result of the study will give focus on teacher-regulated attention strategies that can be used to further the study.

\section{Results and Discussion}

\subsection{Summary of Results}

Questionnaires were used in gathering data to be analyzed. The gathered data were analyzed and arranged through thematic coding. The results are the following:

\subsubsection{What do Teachers Do When They are Losing the Attention/Interest of the Students}

a. Utilizing activities (Giving an individual or group activity)

b. Calling the attention and constant reminding of behavior (Calling the misbehaving students, and giving of warnings) c. Catching attention by being quiet (Lowering down the voice, and being silent or stopping the discussion)

d. Questioning to evaluate (Asking the students about the lesson, and engaging the students in the discussion by giving examples, opinions, and ideas)

e. Infusing humor (making jokes)

f. Using positive and negative reinforcement

(Using positive reinforcement, and use of punishment) 
g. Re-introducing the topic in a more creative way (changing the strategy)

\subsubsection{Challenges in Trying to Sustain the Attention of the Students}
a. Using positive and negative reinforcement
b. Thinking of a strategic way to teach the lesson
c. Knowing the problem
d. Constant reminding to behave

3.1.3. Teachers' reactions/feelings when they lose the attention of the students
a. Questioning the competence
b. Showing/expressing negative emotions
c. Making the students feel accountable
d. Working hard to improve teaching styles

\subsubsection{Indicators of Having Sustained Attention from the Students}

a. Having inquiry and clarification of things

b. Keeping students' attention

c. Participating in the discussion and activity

d. Appreciating the lesson

3.1.5. Value of getting students to feel emotionally secured in your company as a teacher

a. Improving the learning process

b. Strengthening the teacher-student relationship

3.1.6. Ways on getting Students to Trust You and to Feel Emotionally Secured in Your Company as a Teacher

a. Showing of Affection (Offering help, listening to students, sharing personal experiences, caring about their feelings)

b. Making the lesson interesting and having sense of humor during discussion (Making the subject interesting, Using humor)

c. Giving motivating feedback on students' works (Dealing with the students nicely, showing respect, and giving constructive feedback)

d. Acknowledging strengths and weaknesses (Believing in the students' capabilities, and encouraging the students to be better)

\subsubsection{Indicators of Successful Teaching}
a. (Students) Showing retention of the lesson
b. Evaluating students' outcomes and performances
c. Displaying appreciation of the lesson
d. Inquiring and applying the knowledge

\subsubsection{What Teachers Do When They Lose Sustained Academic Connection with Their Students}

a. Reevaluating b. Working for a meaningful learning

c. Incorporating games and different activities

3.1.9. Challenges Teachers Face in Trying to Sustain Academic Connection of the Students

a. Disobedience and misbehaviors in the class

(Showing disinterest in the lesson, and students distracting the discussion)

b. Teaching complex topics

(Delivering hard lessons or topics

Contextualizing the topic)

c. Taking time to prepare the materials and the lesson

(Planning and preparation of materials, visual aids and activities, and sustaining the energy)

d. Dealing with uncontrollable factors (Having students from diverse culture and background, putting emotional state and external factors into consideration, putting classroom ambiance and classroom setup into consideration)

3.1.10. Indicators of Having Sustained Academic Connection with the Students?

a. Showing understanding and mastery of the lesson (Applying the knowledge, showing interest about topic and asking questions, and applying the learned concepts)

b. Learning Independence (Doing the tasks, and fulfillment of class requirements)

c. Meeting the objectives of the lesson (Achieving the objectives, and achieving good grades)

Data also shows the typical classroom setup during the first day of class:

- Sharing some of my experiences when I was their age.

- Introducing myself and giving an overview of the subject.

- Giving students a get-to-know your activity where they describe the person seated next to them as a fruit.

- Being familiar with the teacher.

- Making introductions during the first day

- Telling expectations of both the students and the teacher are set.

- Beginning with a short introduction and background of the school.

- Introducing oneself.

- Establishing a rapport with them during the first few days.

- Play with them and talk to them to make them comfortable with you.

- Initiating on introducing myself and telling them my educational background. 
- Believing in the students that they are already at ease with me.

- Takes time to leave their parents or guardian outside the classroom to be alone with their classmates.

- Takes a lot of effort with animated facial expressions and voice to let them listen and look at you.

- Having orientation.

- Talking about the subject requirements, classroom rules, what are my expectations from the class, and the like.

- Trying to establish my authority as a teacher

- Being quiet and knowing each other hardly for first year students.

- Being noisy for students of higher years.

- Giving of the course outline and the grading system.

- Talking and participating only when teacher tells them to do so.

- Chatting with one another using very loud voices.

- Being noisy and excited during the first few weeks of the school year.

- Being attentive, ready for the class participation.

- Does the assignment and seatwork.

- Trying to be at their best.

- Being attentive in the class during the first few meetings.

- Participating and active in class.

- Students who tried to impress the teacher by asking a lot of questions.

- Having mutual eagerness and everyone is attentive and engaged.

- The students were silent and were just listening to the instructions given to them.

- We usually have a staggered schedule which allows the students to see what Kindergarten or Preschool is all about while also allowing the teachers a chance to evaluate each of the kids to see where the best placement is for them.

- Being quiet most of the times.

- Play and manipulate objects than sit down and listen to teacher

- Beginning the school year by being timid and quite uncomfortable

- Being generally quiet and behaved as they try to have a feel of their classmates and me.

- Anticipating the day's lesson/activity because I believing that there are so many things to share and learn

- Buzzing with excitement, restless and full of energy
- Losing their focus on following school rules

- Reminding the students of how they are supposed to behave when in school

- Changing seats and chatting with seatmates

Generally, introduction and orientation is taking place during the beginning of the class or of the year. There are students who already know each other and this may seem to be problem because students are creating noise due to excitement. Others are timid and shy because they are new in the school and the teacher is not familiar with them. Rapport between the teacher and students is important, and the rapport between students is equally important too.

Data shows the conscious effort of the teachers to make the student emotionally secured and get to trust them in the classroom:

- Greeting each student with a smile.

- Chatting with them during free time, and playing with them

- Offer help willingly

- Telling them that whenever they need help, when they have concerns or any questions, they may ask me anytime

- Making sure I listen to their query even after class

- Listening in their concerns even after the lessons

- Making them see me as often as they can for consultation and I emphasize to them that they can seek advice about their personal life

- Sharing little personal things for them not to hesitate to share with me their thoughts, feelings, and their problems too

- Making them comfortable to talk to me anytime

- Letting them know how they are feeling and trying to process it by talking and helping them to resolve their problems or concerns.

- Spending time with them while they are playing and asking questions about the topics that would interest them

- Laughing with them

- Sharing their sentiments

- Sharing them a part of who I am by telling my own life experiences

- Sharing them personal accounts at certain times and relate my learning on the lesson/ topic at hand

- Reciprocating gestures of love and admiration 
- Making an effort to make lessons varied, interesting, challenging and effective, students feel the emotional security

- Having sense of humor

- Injecting humor in the instruction

- Make awkward situation funny

Students' reactions to teachers' feedback also varies:

- Insisting that they'd be given more explanations as to why their answers are wrong

- Showing resistance

- Seeing them frown

- Getting defensive

- Feeling disappointed

- Being quiet, some students who are feeling so smart show their sarcastic faces

- Getting disappointed

- Asking about the grade of the other group and then blame their group mate who made have a mistake.

- Getting upset

- Showing a sad/puzzled face before scrutinizing his/her answer

- Expressing disbelief through facial expressions but those who are vocal ones they really approach me.

- Explaining to me their side

- Taking it seriously

- Taking it positively while others don't

- Being satisfied with the feedback

- Being sad, but when encouraged that they can do better and that there's possibility of getting two stamps they smile back and just say "okay". I would usually hug them after

- Accepting and agreeing on what I had observed.

- Taking it as a challenge which would make them realize their shortcomings

- Taking it constructively

- Apologizing and saying that they would do better the next time

- Being quiet during an oral feedback and listen

- Brushing it off and taking it as an area for improvement for their next presentation or activity

- Giving me a shy smile

- Welcoming it

- Taking it in stride

These reactions are evidences that teachers should be considerate on student's emotions. As any of the negative feeling might trigger the avoidance of the subject or embarrassment to the students emphasizing the vital role of emotional security to the learning.

\section{Discussion}

Learning is a complex process that involves intelligence, motivation, physical environment, psychological factors, and internal condition of the students. It also involves preparation of teaching plan and materials. Many research suggest ways of how to effectively teach. Westwood [9] summarizes the characteristics of effective teachers as follows:

- have well-managed classrooms where students have the maximum opportunity to learn

- maintain an academic focus

- have high, rather than low, expectations of what students can be helped to achieve

- are business-like and work-oriented

- show enthusiasm

- use strategies to keep students on task and productive

- impose structure on the content to be covered

- present new material in a step-by-step manner

- employ direct (explicit) teaching procedures

- use clear instructions and explanations

- use a variety of teaching styles and resources

- frequently demonstrate appropriate taskapproach strategies

- monitor closely what students are doing

- adjust instruction to individual needs and re-teach where necessary

- provide frequent feedback to students

- use high rates of questioning, to motivate students and to check for understanding.

Effective teaching would not take place if the factors that hinders this are not known, examined, and addressed. It is as important of knowing how to be an effective teacher as knowing what causes teaching to fail.

Effectivity of the teacher is also grounded on trust and security. When the students trust the teachers, everything else follows and the discussion and ideas flows smoothly. Emotional security unblocks the flow of ideas, and opinions during the discussion. It aids the teachers in finding solutions to the poor performance of the students and to other concerns related to learning of the student. Knowing the interests and integrating lessons through meaningful discussion is also a tool to encourage students to participate. 
The first day of class routine greatly affects the rest of the meetings and classes. This is the time where impressions are set and expectations from the teachers and from the students are set. Setting expectations and using varied instructional strategies and materials secures academic connection. Setting expectations put a direction to where each activity to lesson is headed to and what should be given to meet these expectations. Varied instructional strategies and materials aid the teacher in delivering the lesson with clarity and diminish boredom.

Different factors that affects attention and academic connection are shown in the results. Knowing these constraints that hinder the flow of discussion in the classroom will help the facilitators think of a possible way of minimizing or avoiding these factors or rather minimizing the impact of these constraints especially when they are uncontrollable factors like time and the weather. Motivation is effective in getting and sustaining attention. Children are motivated in different ways, so teachers should be creative. It is important to recognize that a child may have a poor attention span or may have a selective attention. It is also imperative to identify the factors that may add to poor attention. Using varied techniques employs focusing on the subject matter or the topic.

More effective teachers utilize instructional strategies that engage students repeatedly throughout the entire lesson. This engagement should begin early in the lesson and continue throughout the lesson introduction, body, and closure. A lecture should be done with the maximum time of thirty minutes before giving an activity that will engage the students in the learning process [1]. Student-centered activities give emphasis to the construction of knowledge by the students through their active participation and involvement. The engagement activities should facilitate the development of knowledge, skills, and attitude that are targeted and identified by the learning objectives.

According to Piaget [8], learning does not occur passively; rather it occurs by active construction of meaning. It means that learners are not passive individuals, they are active part of the classroom dynamics. Constructivism believes in meaningful creation and application of knowledge so therefore teachers should allow their students to apply their knowledge. Therefore, the elimination of fear in making mistakes should be removed for the students to actively take part in the discussion and activities. Social constructivists view learning as a social process. It does not take place only within an individual, nor is it a passive development of behaviors that are shaped by external forces [4]. Learning is a construct where students should be engaged in the reality of things to formulate their own concepts and theory. Best conditions for learning should be provided to maximize the learning opportunities of the students. Therefore, activities and tasks should be well-prepared by teachers to challenge learners where actual experiences will let them conceptualize the materials provided for them. Constructivism as an educational theory believes that teachers should first consider their students' knowledge and allow them to put that knowledge in to practice through actual situations [8]. An oppressive learning environment is not constructivist approach as it hinders the learning of the students in a way that they perform in avoidance of the punishment but not to engage themselves fully in an activity. This environment does not nurture the capabilities of the students.

Actual exposure to concepts through real experiences like classroom tasks and activities foster the creation of meaning. Learning is an active process in which experience has an important role in understanding and grasping the meaning. This view of knowledge does not necessarily reject the existence of the real world, instead it agrees that reality places constrains on the existing concepts and contends that all individuals' knowledge of the world is the interpretations of their experiences [8]. Social interaction is also important to the learners that's why student-student bond also contributes to learner's holistic growth as an individual. Young children's social interaction with adults helps them acquire social meaning of important symbols and how to use them [4].

The study "Teacher behavior and student outcomes: Results of a European Study," identified one of the teacher factors: the classroom environment. This factor comprises five elements, i.e., teacherstudent interaction, student-student interaction, students' treatment by the teacher, competition between students, and classroom disorder [7]. As the data shows, different relationship dynamics affects teaching and learning process in the classroom.

Teachers own construct of meaning also influenced the learners' interpretation of experience. As such, teachers should be careful in planning out tasks and materials to be used in the classroom. Their role is always challenged by shifting realities and students' performance. Teachers are affected by the students' performance in the classroom, and this is manifested in how they handle their class and how they respond to the positive and negative happenings in the classroom. Relationships in the classroom such as student-student relationship and teacher-student relationship are also the bonds that are affecting cycle and flow of learning in the classroom. These bonds are bridge that facilitate learning if it forms a positive feeling for the teacher and the student and may also form a gap for learning if it creates negative feelings. Teaching needs interaction with the students, and every action in this interaction is reciprocated. 
Students are active curriculum planners in a way that they confront the ideas, questions and try to find the answers, and live the curriculum planned by educators for them. In such a way, educators can also test, modify, and develop the curriculum by the contributions of students as observed and confirmed by the educators. This is where negotiation in the curriculum happens [11]. Bruner [11] explains negotiating the curriculum means deliberately planning to invite students to contribute, and to modify, the educational program, so that they will have a real investment both in the learning journey and the outcomes [8].

The use of questions is evident in evaluation if learning occurred. Students should also feel welcomed to ask questions and have the courage to ask questions. This is a kind of communication in a learning environment where confidence is developed and assertiveness is nurtured and this is established if emotional security is also felt by the students within the company of the teachers and his fellow learners. Asking of question should be viewed as a liberating factor of knowing what is wrong and knowing what is there that should be understand.

A teaching environment should be nurturing especially to young learners. It is an obligation to give primacy to the best interests of children and to ensure their optimum development requires that learning environments are welcoming, gender-sensitive, healthy, safe and protective (Education for All, pp 3). Here are the participants' answers on how important emotional security in the classroom:

- Motivating the students to learn

- Contributing a lot in good academic performance.

- Not feeling any anxiety as they engage in the learning process

- Making learning easier

- Finding out what their interests are

- Relating the lesson to certain topics which would pique their interests

- Making the children listen and interact with the teacher in class

- Knowing the students' difficulties and therefore the teacher could adjust to their needs

- Being emotionally secured helps them own their learning and have their own drive to improve

- Helping the students to learn more

- Learning a lot than just listening, taking down notes, and memorizing.

- Fosters learning.

- Coming to school on time and spending hours just listening to the class discussion
- Feeling comfortable to stay inside the classroom

- Pushing the students to naturally open up to you

- Participating willingly in class activities.

- Seeking help from the teacher whenever the students are having difficulties

- Willing to open up

- Talking about their situations openly

- Giving trust and understanding the lesson.

- Approaching the teacher without hesitation.

- Earning respect, love, and trust from the student

- Feeling good whenever I hear the side of the student body either inside the Guidance office or even within the classroom

- Helping the students to reach out to students who are having difficulty understanding the lesson and students who are seen in class as socially awkward.

- Having the students to trust and believe the teacher

- Having higher respect towards you because your value as their teacher and as a person increases

- Showing his/her ability in class

- Learning how to participate in classroom activities without the fear of being judged

- Helping shy students to be confident without the fear of being laughed at

- Feeling secured that there's no harm in asking questions

- Discussing the lesson with ease and students are not afraid to ask things that they don't understand about the lesson

- Acting freely and they will have no reservations about themselves

- Understanding themselves better rather than keep things even ideas to themselves

- Sharing if they find the lesson difficult or not

- Learning without fear of ridicule or judgment

Emotional security establishes connection on attention and academic connection. It builds a safety ground that foster academic achievement and commitment to learning. There are varied ways in establishing emotional security in the classroom. Having a safe environment where there is trust, acceptance, encouragement, and love will get the students to be involved in the teaching-learning 
process. Fear and insecurity is a wall that separates students from a meaningful discussion and learning so the teacher should know how to break this wall. Data shows that students participate enthusiastically, and learning becomes meaningful when they feel they are emotionally secured. At the same time, successful teaching is outright when tasks are carefully planned, monitored and constructive feedback are given after activities. Effects of emotional security on learning is very evident based on the lived experiences of the teachers.

Data shows the conscious effort of the teachers to make the student emotionally secured and get to trust them in the classroom:

- Greeting each student with a smile.

- Chatting with them during free time, and playing with them

- Offer help willingly

- Telling them that whenever they need help, when they have concerns or any questions, they may ask me anytime

- Making sure I listen to their query even after class

- Listening in their concerns even after the lessons

- Making them see me as often as they can for consultation and I emphasize to them that they can seek advice about their personal life

- Sharing little personal things for them not to hesitate to share with me their thoughts, feelings, and their problems too

- Making them comfortable to talk to me anytime

- Letting them know how they are feeling and trying to process it by talking and helping them to resolve their problems or concerns.

- Spending time with them while they are playing and asking questions about the topics that would interest them

- Laughing with them

- Sharing their sentiments

- Sharing them a part of who I am by telling my own life experiences

- Sharing them personal accounts at certain times and relate my learning on the lesson/ topic at hand

- Reciprocating gestures of love and admiration

- Making an effort to make lessons varied, interesting, challenging and effective, students feel the emotional security

- Having sense of humor

- Injecting humor in the instruction

- Make awkward situation funny
Using the lens of Theory of Affect, the importance of emotional security on teaching effectiveness is analyzed in this paper. Affect arises in the midst of in between-ness: in the capacities to act and be acted upon. Affect is an impingement or extrusion of a momentary or sometimes more sustained state of relation as well as the passage (and the duration of passage) of forces or intensities. That is, affect is found in those intensities that pass body to body (human, nonhuman, part-body, and otherwise), in those resonances that circulate about, between, and sometimes stick to bodies and worlds, and in the very passages or variations between these intensities and resonances themselves [3]. In a social context, like school, the theory of affects explains the power of emotional connection between individuals and how the teachers and students affect each other through resonance of emotions. It analyzes how actors (teachers and students) experience, interpret, and respond to their own emotions and feelings produced by successful or unsuccessful exchange efforts in the classroom [5]. This emotional response could be a barrier or an instrument of teaching effectiveness.

Emotional security eliminates negative feelings like fear, and anxiety in the classroom and strengthens positive feelings like trust and confidence. Teachers affect the learning of students as well as students affect the teachers' teaching practices. Emotional security is the object of effect of both the learning and the teaching processes. This object causes the feeling in the classroom.

Establishing emotional security is necessary in teaching because teachers can effectively teach the lesson when the students are confident and don't have any fear or hesitations. It will be easy then to motivate students; to know the students' interests because they are able to share them openly; and students can learn more because the fear of making mistakes and insecurity among students are lessened. Emotional security creates a bond between that teacher and the students that builds trust, respect and confidence. It is easier to encourage students when they trust their teachers and they can understand themselves better by honest feedback.

Teachers are powerful individual in the classroom that influences the emotions of students. They can create negative emotions such a fear and anxiety that can transcend in non-successful teaching and they can create a power of authority in the classroom. On the other hand, students can affects teachers' emotions by resistance, non-compliance of requirements, aloofness, and by being passive or setting walls between the student-teacher relationships. This can affect the teachers' efforts to create a healthy classroom for learning. Between the students and the teacher, the teacher have the more powerful role in establishing emotional security because of his role in the classroom as facilitator and organizer of activities and lessons. This power creates an affective construct 
that influences his students' performance and learning. But this power is challenged by the students' misbehaviors or resistance than can affect his emotions. Therefore, students can make the learning process a struggle for teachers as teachers can blame themselves or gets frustrated by the outcomes of his or her efforts.

Emotional security is a tool that enables teachers to see students' needs so that he or she could maximize available resources in planning the instruction to sustain attention or academic connection during the discussion. Sustaining attention and academic connection should start from the beginning of the class and not only when students are on the edge of losing the connection. Planned instruction should be flexible and must build up challenges and fun for the students for learning is an academic engagement between teachers and students. These considerations can create big impact to the learning process. Indicators of having sustained academic connection and attention are expectations of the students from the students. These expectations affect the teachers causing them to blame themselves if there is failure in sustaining the attention of the students.

Indicators of learning expected by the teachers from the students are also the objects of affect in the classroom. These expectations bring emotions to teachers if ever they are met or not. Meeting the expectations bring happiness or any positive feeling like feeling of achievement for the teachers as well as bringing frustration or self-blaming when they are not met. Teachers are conscious of the effect of emotional security in the students' performance like motivating to learn, knowing students' interest, learning more about the topic, building trust, respect and confidence, overcoming fear, encouraging the student to strive, understanding themselves, improving the learning process, and strengthening the teacher-student relationship.

Effective teachers are concerned about enhancing their student's self-esteem as they achieve more learning. Effective teaching also appreciates the idea of individual differences where students are not pressured to do things against their will and beliefs. When students feel comfortable in the classroom, they will be more likely to take the risks that are necessary for learning, and they will not feel bad about themselves when they make mistakes. Effectiveness also means creating an impact on student's life by making him realize his skills, developing his potentials, and encouraging his critical thinking skills. It means that your teaching abilities and endeavors have effects on the learners. Effective teaching is guiding the student all the way in the process of learning and experiencing knowledge

With such affection and personal attachment to children, every teacher is willing to extend time, effort and resources to make them learn. Sustained learning will, in the end, facilitate their continued knowledgesearch and consistent skill development.

Teaching doesn't end in the four walls of the classroom because there's should be no wall at all in a classroom. It means that an effective teacher reaches out to the students and there are two ways of communication going on. When a student is not doing well in class, it does not mean he is poor. The best thing an effective teacher can do is calling out the student's attention and help him out to learn, knowing the roots of the problem and not giving out conclusion on the student about his ability to learn.

Studies indicate that positive affect can help individual's relationship with others and foster creativity and helps achieve success in life [12].

\section{Conclusion}

Teaching is a complex process and prescribing one effective method to teach is not effective. Emotional security provides ground for effective teaching and open communication which facilitates deeper understanding about the nature students, on how to assist them in learning and how to manage learning better.

Teaching doesn't stop as one lesson ends. It continuously influences the students wherever they go. It could influence also those who are interested to be teachers on how they would do someday in this career. Effective teaching does not necessarily mean that all students like you. What is important is that you made them learn - as they say you cannot satisfy everybody. A good teaching is a strategic way of handling things being a facilitator of learning that utilizes resources to aid teaching-learning process to meet the objectives. It is the beginning of effective teaching that needs to carry out virtues, aspirations, responsibility to the children that will motivate them to work and pursue.

Using of visual aids and varied instructional techniques is important to engage students to learning and to secure academic connection. It aids the teachers to make the students stay in the track of the lesson at the course of the discussion. Connecting lessons with their interests, currents events or issues helps sustain a meaningful learning where students get to see and build concepts through their own experiences and own generation. Linking the lessons with previous lessons is also a way construct significant learning while checking on the retention of the previous ideas.

There are strategies that teachers use to effectively teach the lesson by getting respect, sustained attention and academic connection. These are the core that teachers find important to make teaching effective: Employing discipline and creating motivating activities, Making teaching effective by getting respect, Building an environment that nurture trust, love and confidence, setting expectations and using varied instructional strategies and materials. 
Employing discipline and creating activities is important to get the attention of the students to the topic or the subject. Being firm on the decisions and implementing rules cut-short the behavioral problems inside the classroom.

Having a sense of humor is important not just to make the students laugh but also to build a relaxed atmosphere and to get the students to be focused at the topic. It is also a tool that makes the teaching-learning process meaningful and to flow smoothly. Using of jokes to talk about serious things is also in the culture of the Filipinos.

Setting expectations and using varied instructional strategies and materials secures academic connection. Setting expectations put a direction to where each activity to lesson is headed to and what should be given to meet these expectations. Varied instructional strategies and materials aid the teacher in delivering the lesson with clarity and diminish boredom. Emphasis on making varied instructional materials and strategies of using varied instructional materials should also be given importance on teacher training and teacher curriculum.

Education is shaping the society and pedagogical practices should be examined and evaluated if it contributes to nurturing positive feeling of the learners towards himself and his community. Oppressive methods of teaching hinders academic growth. According to Freire [2], education either functions as an instrument that is used to facilitate the integration of the younger generation into the logic of the present system and bring about conformity to it, or it becomes "the practice of freedom," the means by which men and women deal critically and creatively with reality and discover how to participate in the transformation of their world.

The academic success of students is influenced by the emotional security they have in the company of the teachers. The teacher's effectiveness is dependent on the interaction of the teacher with the student, student and teacher interaction with the subject matter, and their interaction on the learning outcomes. These interactions happen during academic connection.

Having a safe environment where students feel involved and respected will reduce discipline issues, increase students' motivation, and ultimately enhance learning. Students know when a teacher genuinely cares about their success and will often work harder when they feel the respect and support from their teacher.

Oppressive form of pedagogy (like using of negative reinforcements) are still evident on the gathered data. It is also reflected that teachers are oppressed in preparation of their materials that points at the fact that there should something to be done in the load credits of the teachers to remove constraints for them to effectively manage the delivery of the lesson. Controlled factors such as physical space and infrastructures should also be given importance by educators as these can also hinder or foster learning.

Emotional security is a powerful tool on making the teaching-learning process effective. Teachers should be able to manage their own emotions as it can traverse on the learning process that can affect students' performance. They are considered powerful in influencing the emotions of students.

\section{References}

[1] Bulger, S.M., Mohr D.J., Walls, R.T., (1999). "'Stack the Deck in Favor of Your Students by Using the Four Aces of Effective Teaching" The Journal of Effective Teaching, 2002, Vol. 5, No. 2. Retrieved at: https://www.uncw.edu/ jet/articles/bulger/

[2] Freire, P., (2005). Pedagogy of the Oppressed. The Continuum International Publishing Group Inc, New York.

[3] Gregg, M., Seigworth, M., (2010). The Affect Theory Reader. Duke University Press, London. Walls, R.T. (1994). Concepts of learning: 99 truths. Emmitsburg, MD: National Emergency Training Center.

[4] Kim, B., (2001). Social Constructivism. In M. Orey (Ed.), Emerging perspectives on learning, teaching, and technology. Available Website: http://www.coe.uga.edu/ epltt/SocialConstructivism.htm.

[5] Lawler, E. J., (2001). "An affect theory of social exchange" [Electronic version]. American Journal of Sociology 107(2), 321-352.

[6] Mithaug, D. et al., (2002). Self-determined Learning Theory: Construction, Verification, and Evaluation, Routledge, New York.

[7] Panayiotou, A., Kyriakides, L, Creemers, B, et al. "Teacher Behavior and Student Outcomes: Results of a European Study," Retrieved through: https://www.ucy.ac. cy/esf/documents/data/esf/Publications/2014_teacher_beha vior_and_student_outcomes.pdf.

[8] R.J. Amineh, and H. Davatgari, "Journal of Social Sciences, Literature and Languages" Review of Constructivism and Social Constructivism, 1(1), pp. 9-16, 30 April 2015.

[9] Spears, W.L. (2017). Connecting Emotions to Behavioral Outcomes. Georgia Southern University. Dissertation. Retrieved at: https://digitalcommons.georgia southern.edu/cgi/viewcontent.cgi?referer=https://www.goo gle.com.ph $/ \&$ httpsredir=1\&article $=2447 \&$ context $=$ etd

[10] Westwood, P. (1996). Effective Teaching. Australian Journal of Teacher Education, 21(1).

[11] Bruner, J. S. (1990) Acts of Meaning. Cambridge: Harvard University Press.

[12] Moran, G. S., \& Nemec, P. B., (2013). Walking on the sunny side: What positive psychology can contribute to psychiatric rehabilitation concepts and practice. Psychiatric Rehabilitation Journal, 36(3), 202-208. http:// dx.doi.org/10.1037/prj0000012. 